\title{
Damage Localization of Piles Based on Complex Continuous Wavelet Transform: Numerical Example and Experimental Verification
}

\author{
Wenting Zheng, ${ }^{1,2}$ Sifan Wang, ${ }^{2}$ Chengxu Lin, ${ }^{2}$ Xianying $\mathrm{Yu}^{2}$ and Jingliang Liu ${ }^{2}{ }^{2}$ \\ ${ }^{1}$ College of Civil Engineering, Fujian University of Technology, Fuzhou 350118, China \\ ${ }^{2}$ College of Transportation and Civil Engineering, Fujian Agriculture and Forestry University, Fuzhou 350002, China
}

Correspondence should be addressed to Jingliang Liu; liujingliang@fafu.edu.cn

Received 10 October 2019; Revised 11 January 2020; Accepted 18 February 2020; Published 13 June 2020

Academic Editor: Emiliano Mucchi

Copyright (c) 2020 Wenting Zheng et al. This is an open access article distributed under the Creative Commons Attribution License, which permits unrestricted use, distribution, and reproduction in any medium, provided the original work is properly cited.

\begin{abstract}
A new signal processing method called complex continuous wavelet transform (CCWT) is introduced in this paper to localize pile damage because it clearly reveals inherent characteristics of response signals. In this method, CCWT is first performed on the response signal to obtain the wavelet coefficient matrix. The resultant coefficients are then employed to calculate phase angles at different frequency bands with an aim of pile damage localization. However, the CCWT method is only demonstrated via laboratory tests on pile specimens, and its application on actual piles has not been examined. Moreover, various factors such as pile-soil interaction need to be considered when the CCWT method is applied on actual piles. To address these issues, a numerical example of 3D finite element pile model followed by a parameter analysis and an experimental verification on an actual pile are investigated. The results demonstrate that the CCWT method is capable of localizing pile damage under different damage scenarios. However, there are still some interference points in the grayscale images of phase angles and the reduction of interference points needs to be addressed by mutual verification with other pile damage detection methods and engineering experience.
\end{abstract}

\section{Introduction}

Pile integrity assessment has provided a promising approach for pile quality control. In recent years, various methods, e.g., pulse-echo, transient dynamic response, vibration, and bending wave, have been proposed for pile integrity assessment [1-5]. These methods can be classified into two categories: static and dynamic approaches [6]. However, static pile testing is time-consuming and inconvenient since a large amount of surcharge load equipment is needed [7]. By contrast, dynamic pile testing including low strain testing (LST) and high strain testing (HST) has been widely accepted for pile quality assessment due to its reliability $[8,9]$. In particular, LST works well on pile quality assessment because of its low cost, easy operation, flexibility, and minor damage to pile body [8]. For example, Hou et al. [10] used
LST to identify the pile defects with different damage types and positions. Zheng et al. [11] proposed an analytical method to localize damage of a thin-walled pipe pile based on LST, in which the coupling of the pile and viscoelastic soil vibrations are considered. Up to now, the LST methods, including sonic echo (SE) and impulse response (IR) approaches, have been developed rapidly for damage localization on a basis of one-dimensional wave theory [12, 13]. The principle of the SE method is to determine the position of impedance change by calculating the time difference between the incident wave and reflected wave. That is to say, the reflected wave will be generated in the damaged section and the damage can be localized according to the computing of the time difference if the cross-section decreases at a certain distance below the pile head sharply. However, the amplitude change of the reflected wave caused by pile defects 
is often concealed by the incident wave; hence, the damage positions of the pile cannot be estimated well by using the amplitude information alone. By contrast, the phase information is more sensitive to damage position, and signal processing methods such as continuous wavelet transform (CWT) can be used to localize pile damage due to its advantage on phase information extraction. For example, Xu et al. [14] introduced the synchrosqueezing wavelet transformation (SWT) to identify the reflection time of the response signal from the pile bottom and eliminate noise as well, leading to an enhancement of the accuracy of pile damage localization. $\mathrm{Ni}$ et al. $[15,16]$ used the CWT to perform a series of nondestructive tests on piles, but the minor damage of the pile embedded in soil was not experimentally examined. The complex continuous wavelet transform (CCWT) was also employed to estimate the lengths and damage positions of piles by extracting phase angles [12]. However, the CCWT-based damage localization method is only demonstrated via laboratory tests on pile specimens and its application on actual piles has not been investigated yet. Moreover, the effectiveness and accuracy of the CCWT method on pile damage localization are affected by various factors such as soil-pile interaction, noise intensity, damage extent, and damage position [17]. Thus, it is essential to perform a parameter analysis to investigate the relationship between the damage localization results and the factors mentioned above.

In this paper, CCWT is first introduced to extract the phase information from the response signals. Then, the extracted phase information is used to establish phase angles, by which the phase angle turning points are highlighted and then the specific damage position of the pile body is localized. A numerical example of a concrete pile and a test of an actual pile installed in soil are carried out to illustrate the proposed method. The results demonstrate that the method can localize pile damage effectively. A parameter analysis is also performed to investigate the influence of damage position on the accuracy of pile localization, and the results show that the accuracy of damage localization increases when the damage approaches the middle of the pile body. In addition, the error is possible to increase tremendously if the distance between the damage position and the pile head is less than a quarter of the pile length. The contributions of this paper is stated as follows: (1) Since the pile damage localization based on CCWT is only demonstrated via laboratory tests and its application on actual piles has not been verified, the CCWT is applied on an actual pile to demonstrate its effectiveness and accuracy. (2) A parameter analysis is performed to investigate the impact of damage position on the accuracy of the CCWT method.

The rest of this paper is organized as follows. The methodologies, including LST and CCWT, and the principle of pile damage localization are presented in Section 2. A numerical example and a parameter analysis are performed in Section 3 to verify the accuracy and effectiveness of the CCWT-based pile damage localization method, while an experimental verification on an actual pile is investigated in Section 4. Conclusions are drawn in Section 5.

\section{Methodology}

2.1. Low Strain Testing. LST as a dominant nondestructive testing method is based on one-dimensional elastic theory. In LST, an impulse load is applied on the top of a pile and the resultant response signals are measured by the sensors preinstalled on the pile head. Normally, the incident wave is generated at the pile head and then spreads along the pile with the form of stress wave. The stress wave would be reflected when it arrives at the damaged position or the bottom of the pile. Thus, the acceleration response signal measured at the pile head could be a superposition of the incident wave, the reflected wave and random noises. For a better interpretation, the measured acceleration response signal can be converted to velocity signal, which also provides a great amount of information for pile damage localization. After that, the pile integrity assessment can be realized by an analysis of the amplitude and phase feature hidden in the response signal.

Assume that the pile is a one-dimensional elastic rod as shown in Figure 1. In this model, $L, A, E$, and $\rho$ represent length, cross-sectional area, Young's modulus, and mass density, respectively. $c$ is the wave propagation velocity and can be solved by $c^{2}=E / \rho$.

The stress equilibrium equation in the direction of $x$ is established as equation (1) if an arbitrary element $\mathrm{d} x$ is taken as an object to be analyzed:

$$
\sigma_{x} A-\left(\sigma_{x}+\frac{\partial \sigma_{x}}{\partial x} \mathrm{~d} x\right) A=-\rho A \mathrm{~d} x \frac{\partial^{2} u}{\partial t^{2}}
$$

where $u$, $t$, and $\sigma_{x}$ represent the displacement, time, and section stress, respectively.

Then, the stress-strain relationship $\left(\sigma_{x}=E(\partial u / \partial x)\right.$, $\left(\partial \sigma_{x} / \partial_{x}\right)=E\left(\partial^{2} u / \partial x^{2}\right)$, and $\left.c^{2}=E / \rho\right)$ is substituted into equation (1), leading to the one-dimensional wave propagation equation expressed as follows [14]:

$$
c^{2} \frac{\partial^{2} u}{\partial x^{2}}-\frac{\partial^{2} u}{\partial t^{2}}=0
$$

It should be noted that the change of the cross-section area $(A)$ is possible to cause the variance of the wave impedance $(Z)$. Assuming that the impedance changes from $Z_{1}$ (intact section) to $Z_{2}$ (damaged section), the relationship between the particle velocity of the reflected wave $v_{r}$ and that of the incident wave $v_{i}$ can be expressed as follows:

$$
v_{r}=\left(\frac{Z_{1}-Z_{2}}{Z_{1}+Z_{2}}\right) v_{i}
$$

where $Z_{1}=\rho c A_{1}$ and $Z_{2}=\rho c A_{2} . A_{1}$ and $A_{2}$ represent the cross-section areas of the intact section and damaged section, respectively.

2.2. Complex Continuous Wavelet Transform. CWT is an advanced method for time-frequency analysis with adjustable windows at various time instances [18]. It allows the selection of a longer or shorter time interval when more precise lowfrequency or high-frequency information is needed. Owing to that the complex wavelet parent function is sensitive to phase information, CCWT was utilized by $\mathrm{Ni}$ et al. [12] to reveal 


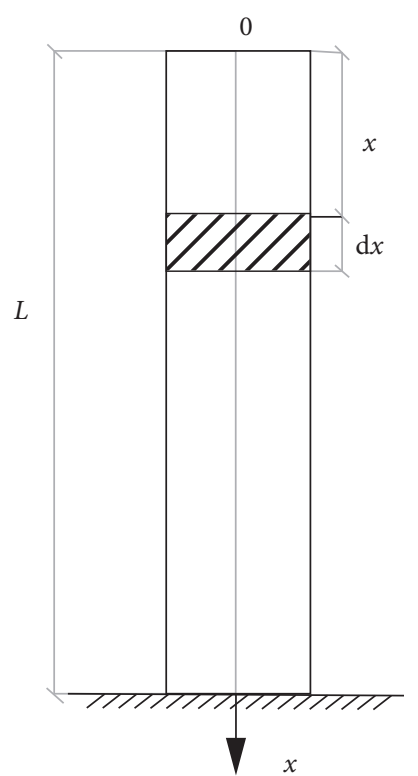

FIgURe 1: One-dimensional elastic rod.

phase angles in the time-frequency representation of response signals measured on the pile head. It is noted that the selection of parent wavelet function has a significant impact on timefrequency representations. Fortunately, the complex Gaussian wavelet is appropriate for tracking local features of nonstationary signals since it has an excellent time-frequency concentration. In addition, complex Gaussian wavelet transform was used by $\mathrm{Ni}$ et al. to perform CCWT and had a success on damage localization of both simulated and experimental piles [12]. Thus, the complex Gaussian function is selected as parent wavelet function in this paper and its mathematical expression is shown as follows:

$$
\psi(t)=C_{p} e^{t^{2}} e^{-j t},
$$

where $C_{p}$ is the scaling parameter and $\psi(t)^{(p)}$ is the $p$-th derivative of $\psi(t)$.

If $\psi$ is a given square-integrable parent complex wavelet function and satisfies the admissibility condition, the CCWT of an arbitrary signal $s(t)$ can be defined as

$$
W_{s}(a, b)=\int_{-\infty}^{+\infty} s(t) \frac{1}{\sqrt{a}} \overline{\psi\left(\frac{t-b}{a}\right)} \mathrm{d} t,
$$

where $a$ and $b$ are the scale factor and the dilation factor, respectively. $\overline{\psi((t-b) / a)}$ represents the complex conjugate of $\psi((t-b) / a)$.

On the basis of equation (5), the instantaneous phase angle $\phi(a, b)$ of $W_{s}(a, b)$ is calculated as

$$
\phi(a, b)=\arctan \left(\frac{W_{I}(a, b)}{W_{R}(a, b)}\right),
$$

where $W_{I}(a, b)$ and $W_{R}(a, b)$ represent the imaginary part and the real part of $W_{s}(a, b)$, respectively.

\subsection{Pile Damage Localization Based on CCWT. The CCWT-} based pile damage localization method is presented here, and the flowchart of it is shown in Figure 2. In this method, the CCWT is performed on the measured response signal at first and the resultant phase angles of the wavelet coefficients are solved according to equation (6). By mapping these phase angles into the time-frequency plane, the phase angle curve exhibits a set of equidistant lines in the time-frequency plane when the material of the pile body is uniform and undamaged. By contrast, there will be an appearance of "crossing points" when the pile is damaged. However, the crossing points can be recognized as phase angle turning points only when the energy related to the crossing point exists [19]. Otherwise, they are recognized as fake points. After the phase angle turning points are found, the time difference between the phase angle turning point and the pile head, denoted as $\Delta t_{n}$, is calculated. Then, the distance from the damage position to the pile head, expressed as $L_{n}$, is computed using the following equation [12]:

$$
L_{n}=\frac{1}{2} \times c \times \Delta t_{n}
$$

\section{Numerical Example}

3.1. Simulation of a Concrete Pile with Pile-Soil Interaction. The 3D finite element (FE) model of a pile as shown in Figure 3 was developed using ABAQUS [20]. The materials of pile body and soil are concrete and clay, whose properties are presented in Table 1. The length of the concrete pile is $20 \mathrm{~m}$, of which $18 \mathrm{~m}$ is buried into soil, while the diameter of the pile is $1 \mathrm{~m}$. Due to the material of the pile body being homogeneous and its slenderness ratio being far greater than 5 , the one-dimensional wave propagation theory is appropriate to be used for pile integrity assessment. The surrounding soil is 5 times the diameter of the pile, which is large enough to ignore the influence of the waves reflected from the far-field boundary [15, 21, 22]. In this model, face-to-face contact is adopted to simulate the relationship between the pile and soil. Actually, two kinds of contact behaviors, including tangential behavior and normal behavior, are considered. The friction coefficient of tangential behavior is set to be 0.3 , while the normal behavior is defined as hard touching. To be specific, the horizontal displacement of the soil is restrained and the bottom of the soil is completely consolidated. By contrast, the horizontal displacement of the pile body is restrained and the vertical displacement of the pile body is free. For simplicity, the damage type of the pile body is defined as necking, with the diameter of the necking section set as $0.95 \mathrm{~m}$. That is to say, the damage degree of the necking segment is $10 \%$. The damaged segment is $0.5 \mathrm{~m}$ high and located at 9 9.5 $\mathrm{m}$ from the top of the pile.

Before the dynamic analysis, the gravity loads of the pile and soil are both considered and applied to the simulated model. Then, an impulsive load of $5 \mathrm{kN}$ is applied to the center point of the pile head (Node 30 in Figure 3) and the duration is $0.1 \mathrm{~ms}$. The time interval is set to be $0.2 \mathrm{~ms}$, and the total duration of time is defined as $20 \mathrm{~ms}$. Thus, the velocity response signal of the reflected wave near the center point of the pile top (Node 543) is obtained by implicit dynamic analysis and shown in Figure 4. 


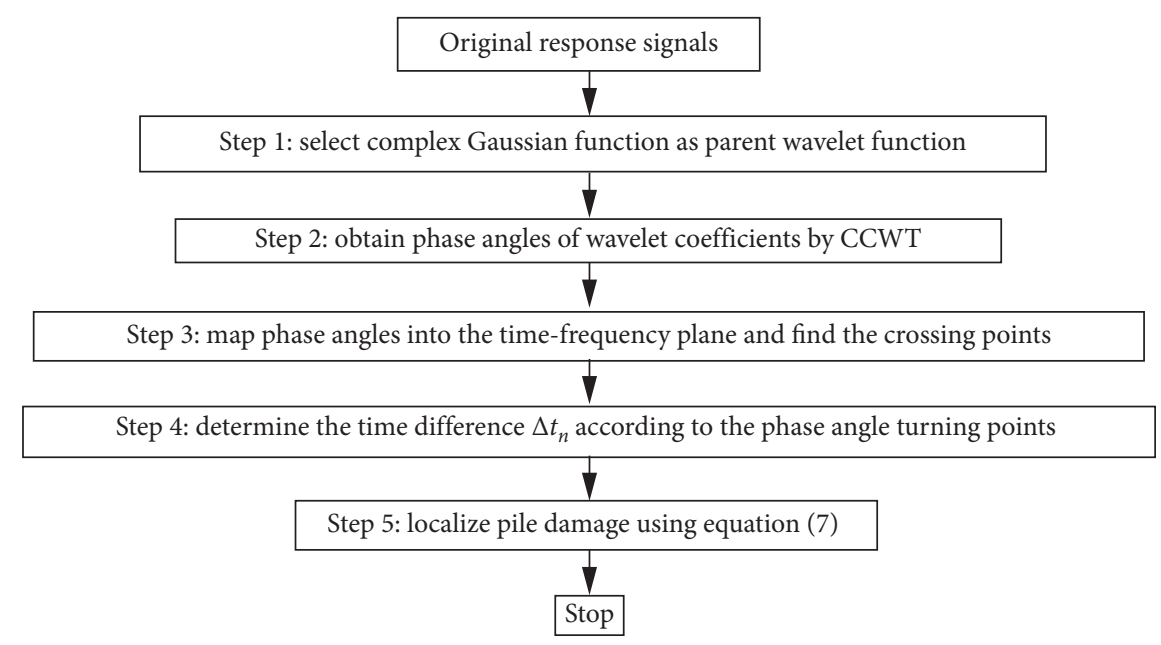

Figure 2: Flowchart of pile damage localization.

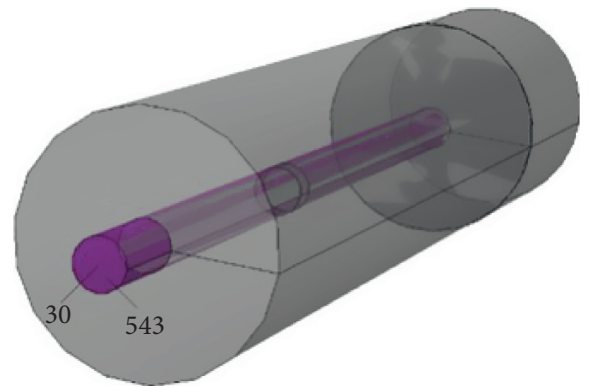

FIGURE 3: FE model of the damaged pile (purple and grey indicate the pile body and soil, respectively).

TABle 1: Material properties of the pile and soil.

\begin{tabular}{lcc}
\hline Properties & Concrete pile & Soil \\
\hline Young's modulus & $3.75 \times 10^{4} \mathrm{MPa}$ & $6.0 \mathrm{MPa}$ \\
Poisson's ratio & 0.167 & 0.4 \\
Density & $2400 \mathrm{~kg} / \mathrm{m}^{3}$ & $1750 \mathrm{~kg} / \mathrm{m}^{3}$ \\
Friction angle & - & $20^{\circ}$ \\
Cohesion yield stress & - & $25 \mathrm{kPa}$ \\
\hline
\end{tabular}

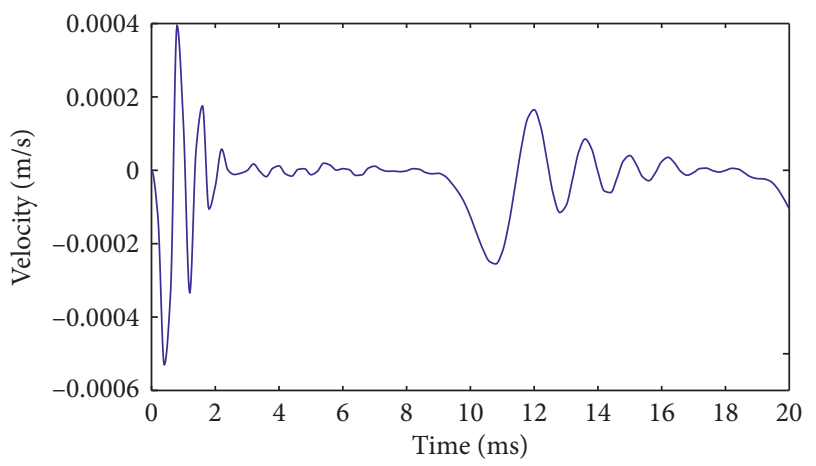

FIgURE 4: Velocity response signal.

3.2. Pile Damage Localization. With the complex Gaussian wavelet selected as parent wavelet function, the CCWT is performed on the solved velocity response signal shown in
Figure 4 and the resultant wavelet scalogram is plotted in Figure 5.

The phase angle is calculated by using equation (6) and then mapped into the time-frequency plane. The resultant grayscale of the phase angles is shown in Figure 6, with white color denoting 180 degree $(\pi)$ of the phase angle and black color indicating -180 degree $(-\pi)$ of the phase angle, respectively. According to the energy-concentrating areas displayed in Figure 5, the frequency band is limited in the range from $200 \mathrm{~Hz}$ to $2000 \mathrm{~Hz}$ and the time range is restricted in the scope of $0.6 \mathrm{~ms}$ to $11.1 \mathrm{~ms}$. On the basis of the determination of the time range and frequency band, a specific area as shown in Figure 6 is defined for the searching of phase angle turning points. It can be seen from Figure 6 that there are three crossing points (Points 1, 2, and 3), with their corresponding frequencies being $810 \mathrm{~Hz}, 1174 \mathrm{~Hz}$, and $600 \mathrm{~Hz}$, respectively. In addition, there is another point (Point 4) corresponding to $0.6 \mathrm{~ms}$ in Figure 6. Point 4 indicates the time instance when the incident wave reaches the top of the pile. To further validate these three crossing points, the time-phase angle curves at the specific frequencies of $810 \mathrm{~Hz}, 1174 \mathrm{~Hz}$, and $600 \mathrm{~Hz}$ are calculated and displayed in Figures 7-9, respectively. As shown in Figure 7, the time instance at $4.85 \mathrm{~ms}$ is exactly a phase angle turning point and the time duration between Point 4 and Point 1 , denoted as $\Delta t_{1}$, is $4.25 \mathrm{~ms}(4.85-0.6=4.25 \mathrm{~ms})$. Similarly, the time durations between Point 4 and Points 2 and 3 are $7.18 \mathrm{~ms}$ and $7.62 \mathrm{~ms}$, respectively. Since the wave propagation velocity is $3953 \mathrm{~m} / \mathrm{s}$ by solving $c=\sqrt{E / \rho}$, the distance between the damaged positions and the pile head $\left(L_{1}, L_{2}\right.$, and $\left.L_{3}\right)$ is calculated to be $8.40 \mathrm{~m}, 14.19 \mathrm{~m}$, and $15.06 \mathrm{~m}$ by using equation (7). Compared with the actual damage position ( $9 \mathrm{~m}$ from the top of the pile model), Point 1 is the real phase angle turning point and the damage localization result $\left(L_{1}=8.40 \mathrm{~m}\right)$ has a relative error of $6.67 \%$.

3.3. Parameter Analysis. In Section 3.2, only a case of single damage position at $9 \mathrm{~m}$ from the top of the pile is performed. In order to study the influence of damage position on 


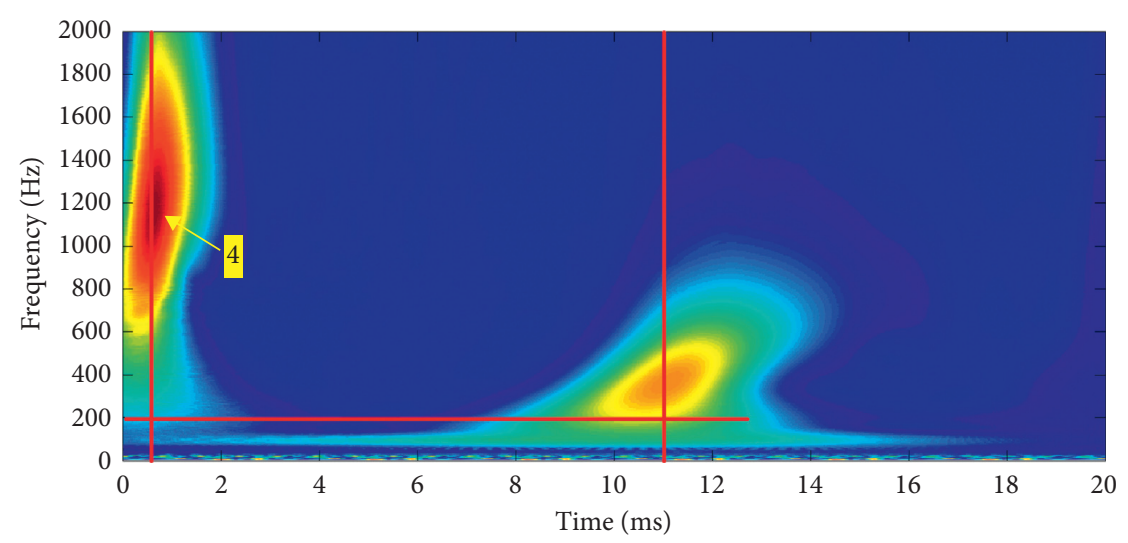

FIGURE 5: Wavelet scalogram of the velocity response signal.

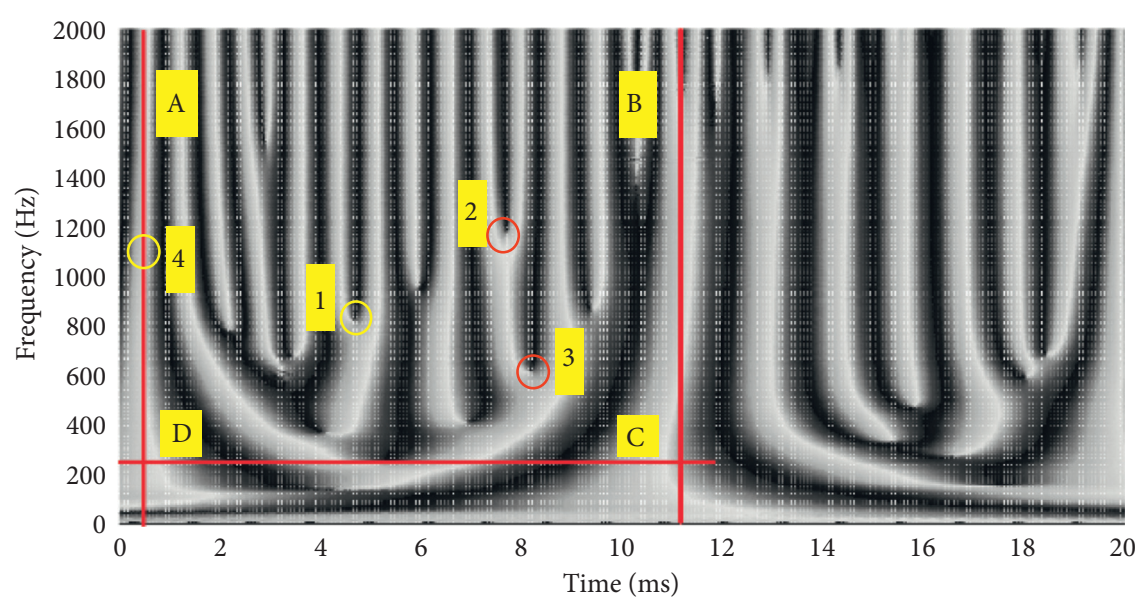

FIGURE 6: Grayscale images of phase angles.

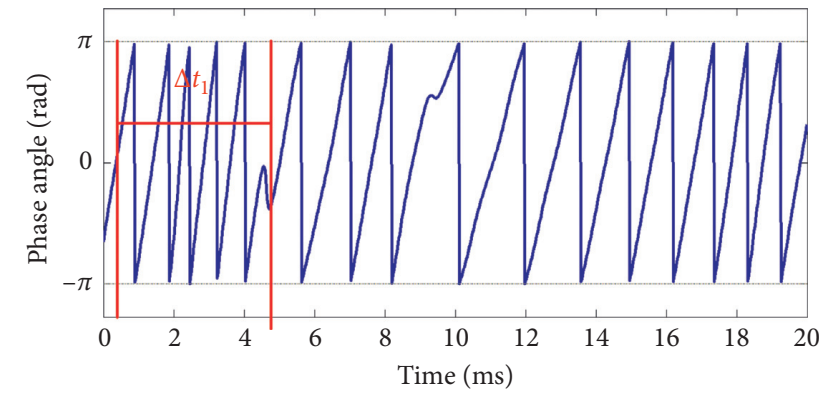

Figure 7: Time-phase angle curve with the frequency of $810 \mathrm{~Hz}$.

damage localization results, 12 damage scenarios, expressed as DS1 DS12, are designed and detailed in Table 2. Although there are various damage types of pile body, only necking of section segments is considered in this paper because of simplicity.

The damage localization results at DS1 DS12 are shown in Table 3. As illustrated in Table 3, the proposed CCWT method successfully detects the damage positions of the pile body under various damage scenarios mentioned above, and the relative errors fall in the range of $6.67 \%$ to $14.33 \%$. Moreover, the relative error becomes smaller when the damage position approaches the middle of the pile body, e.g.,

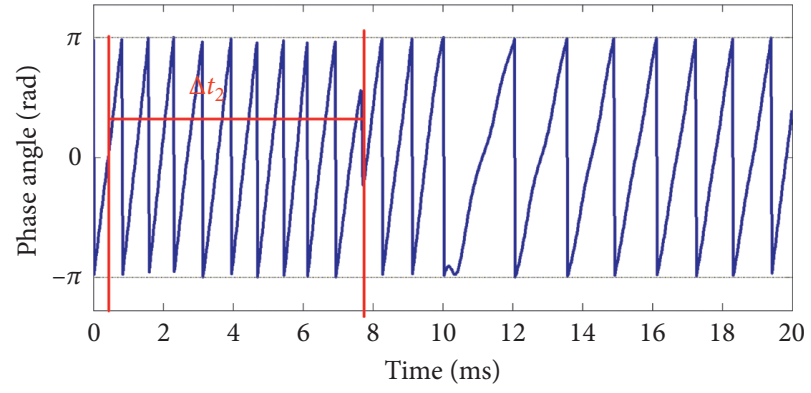

FIGURE 8: Time-phase angle curve with the frequency of $1174 \mathrm{~Hz}$.

DS6 DS8. However, the accuracy of the damage localization results has a dramatic decrease when the damage position approaches the top of the pile, especially when the distance between the damage position and the pile head is less than a quarter of the pile length. The main reason for this phenomenon is addressed as follows. The stress wave signal obtained at the pile head is usually an amplitude-modulated and frequency modulated signal and its amplitude/energy is large because of the incident wave excited by a hammer at the top of the pile. Therefore, the phase information which indicates the damage located at the vicinity of the pile head is 


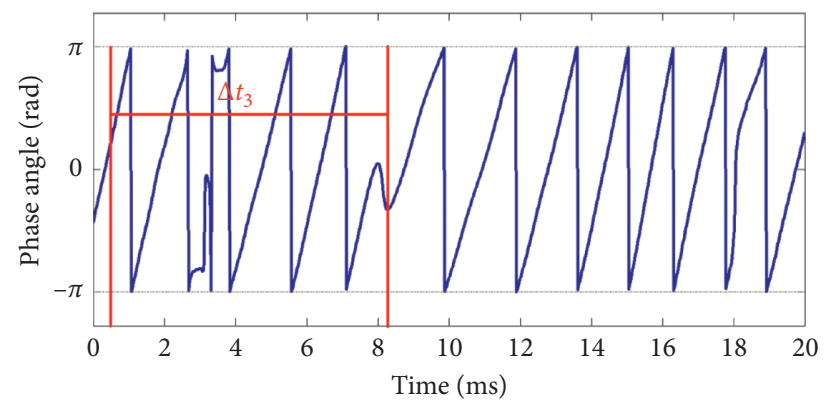

Figure 9: Time-phase angle curve with the frequency of $600 \mathrm{~Hz}$.

TABle 2: Damage scenarios of the simulated pile.

\begin{tabular}{lcccc}
\hline Damage scenarios & Theoretical damage position & Types of damage & Diameter of damaged section (m) & Types of incentives \\
\hline DS1 & $3 \mathrm{~m}$ from pile top & Necking & 0.95 & Impulse \\
DS2 & $4 \mathrm{~m}$ from pile top & Necking & 0.95 & Impulse \\
DS3 & $5 \mathrm{~m}$ from pile top & Necking & 0.95 & Impulse \\
DS4 & $6 \mathrm{~m}$ from pile top & Necking & 0.95 & Impulse \\
DS5 & $7 \mathrm{~m}$ from pile top & Necking & 0.95 & Impulse \\
DS6 & $8 \mathrm{~m}$ from pile top & Necking & 0.95 & Impulse \\
DS7 & $9 \mathrm{~m}$ from pile top & Necking & 0.95 & Impulse \\
DS8 & $12 \mathrm{~m}$ from pile top & Necking & 0.95 & Impulse \\
DS9 & $15 \mathrm{~m}$ from pile top & Necking & 0.95 & Impulse \\
DS10 & $16 \mathrm{~m}$ from pile top & Necking & 0.95 & Impulse \\
DS11 & $17 \mathrm{~m}$ from pile top & Necking & 0.95 & Impulse \\
DS12 & $18 \mathrm{~m}$ from pile top & Necking & & Impulse \\
\hline
\end{tabular}

TABLe 3: Damage localization results under different damage scenarios.

\begin{tabular}{lcccc}
\hline Damage scenarios & Theoretical damage position & Damage localization result & Relative error (\%) & Number of fake crossing points \\
\hline DS1 & $3 \mathrm{~m}$ from pile top & $2.57 \mathrm{~m}$ from pile top & 14.33 & 4 \\
DS2 & $4 \mathrm{~m}$ from pile top & $3.44 \mathrm{~m}$ from pile top & 14 & 4 \\
DS3 & $5 \mathrm{~m}$ from pile top & $4.35 \mathrm{~m}$ from pile top & 73 & 3 \\
DS4 & $6 \mathrm{~m}$ from pile top & $5.53 \mathrm{~m}$ from pile top & 7 & 3 \\
DS5 & $7 \mathrm{~m}$ from pile top & $6.51 \mathrm{~m}$ from pile top & 6.88 & 2 \\
DS6 & $8 \mathrm{~m}$ from pile top & $7.45 \mathrm{~m}$ from pile top & 6.67 & 2 \\
DS7 & $9 \mathrm{~m}$ from pile top & $8.40 \mathrm{~m}$ from pile top & 7.75 & 2 \\
DS8 & $12 \mathrm{~m}$ from pile top & $11.07 \mathrm{~m}$ from pile top & 7.8 & 3 \\
DS9 & $15 \mathrm{~m}$ from pile top & $13.83 \mathrm{~m}$ from pile top & 8.6 & 3 \\
DS10 & $16 \mathrm{~m}$ from pile top & $14.63 \mathrm{~m}$ from pile top & 9.30 & 3 \\
DS11 & $17 \mathrm{~m}$ from pile top & $15.42 \mathrm{~m}$ from pile top & 9.39 & 3 \\
DS12 & $18 \mathrm{~m}$ from pile top & $16.31 \mathrm{~m}$ from pile top & & \\
\hline
\end{tabular}

masked by the oversize energy and the accuracy of pile damage localization is affected [23].

\section{Experimental Verification}

4.1. Introduction of an Actual Pile. In order to verify the application of the proposed damage localization method on actual piles, a LST of a real full-scale pile in Nanping City, Fujian Province of China, is performed. The pile is a circular reinforced concrete pile with a diameter of $2 \mathrm{~m}$ and a length of $19.8 \mathrm{~m}$. Therefore, the length-diameter ratio of the pile is 9.4 , which satisfies the premise of one-dimensional wave theory. Before the test, the damage position of the pile was confirmed $8 \mathrm{~m}$ away from the pile head by using the ultrasonic emission method, which is also taken as the theoretical result for comparison. The rig of this LST is shown in Figure 10. The response signal is excited by a hammer at the top and then measured by using an ICP accelerometer with a sensitivity of $19.8 \mathrm{mV} / \mathrm{m} / \mathrm{s}^{2}$. The data acquisition system used here is a pile integrity tester (PIT) manufactured by the Pile Dynamics Inc Company in the USA (http://www.pile.com). The time interval of the measured acceleration response is $22.2 \mu \mathrm{s}$; that is to say, the sampling frequency is around $45 \mathrm{kHz}$. By integrating the collected acceleration data, the velocity curve is obtained and shown in Figure 11. 


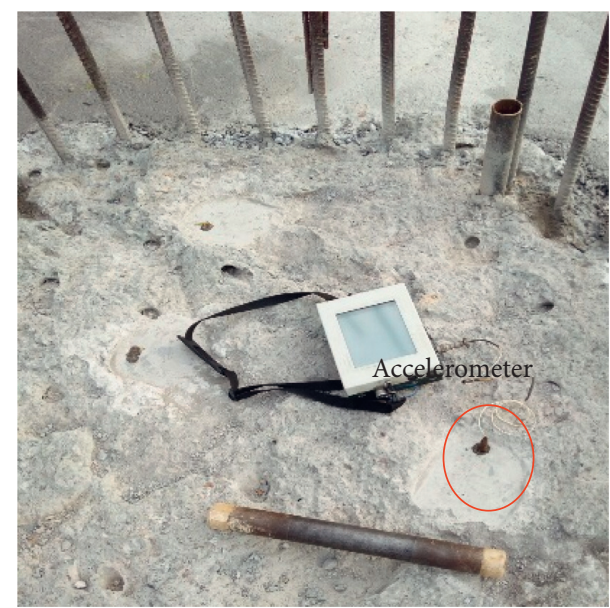

Figure 10: Setup of the LST.

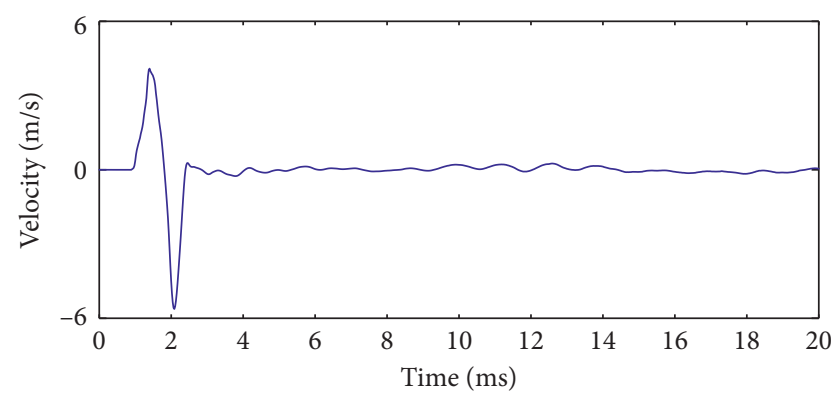

FIgURE 11: Velocity response signal.

4.2. Damage Localization. The CWT is applied to the velocity signal shown in Figure 11, and the resultant wavelet scalogram is plotted in Figure 12. It can be seen from Figure 12 that the energy in the range of $200 \mathrm{~Hz}$ to $1600 \mathrm{~Hz}$ is denser/brighter than that in other frequency bands. Thus, the main frequency range to be analyzed can be set between $200 \mathrm{~Hz}$ and $1600 \mathrm{~Hz}$. In addition, there are two energyconcentrating points at $2 \mathrm{~ms}$ and $12 \mathrm{~ms}$ in Figure 12, which represents the time instance when the incident wave and reflected wave reach the top of the pile, respectively. Hence, the time-frequency analysis is suggested to be strictly restricted in the ranges of $200 \mathrm{~Hz}$ to $1600 \mathrm{~Hz}$ and $2 \mathrm{~ms}$ to $12 \mathrm{~ms}$, which is also defined as a specific area with a name of ABCD.

Similar to the damage localization process in Section 3.2, CCWT with complex Gaussian wavelet as parent wavelet is used to calculate the phase angles and shown in Figure 13. As seen in Figure 13, there are three crossing points in the specific area of $A B C D$ and the corresponding frequencies are $440 \mathrm{~Hz}, 968 \mathrm{~Hz}$, and $418 \mathrm{~Hz}$, respectively. In addition, there is another point corresponding to $2 \mathrm{~ms}$, which is denoted as Point 8 in Figure 13. Point 8 indicates the time instance when the incident wave reaches the top of the pile. The three time-phase angle curves at the specific frequencies of $440 \mathrm{~Hz}$, $968 \mathrm{~Hz}$, and $418 \mathrm{~Hz}$ are displayed in Figures $14-16$, respectively. As shown in Figure 14, the time instance at $6.5 \mathrm{~ms}$ is exactly a phase angle turning point and the time duration between Point 8 and Point 5 , denoted as $\Delta t_{1}$, is $4.5 \mathrm{~ms}$ $(6.5-2=4.5 \mathrm{~ms})$. Similarly, the time durations between

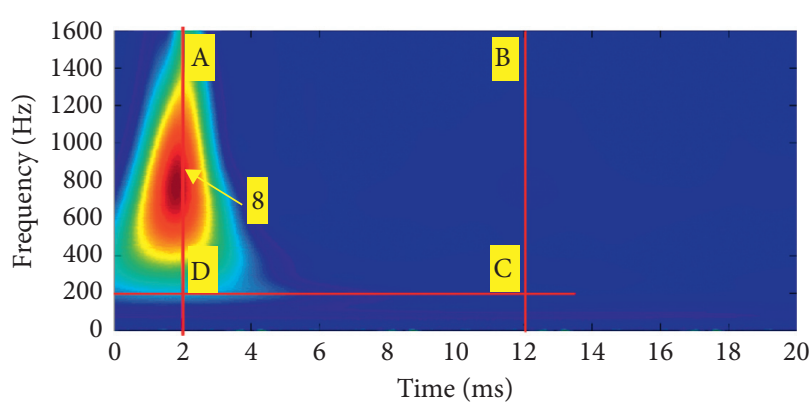

Figure 12: Wavelet scalogram of the velocity response signal.

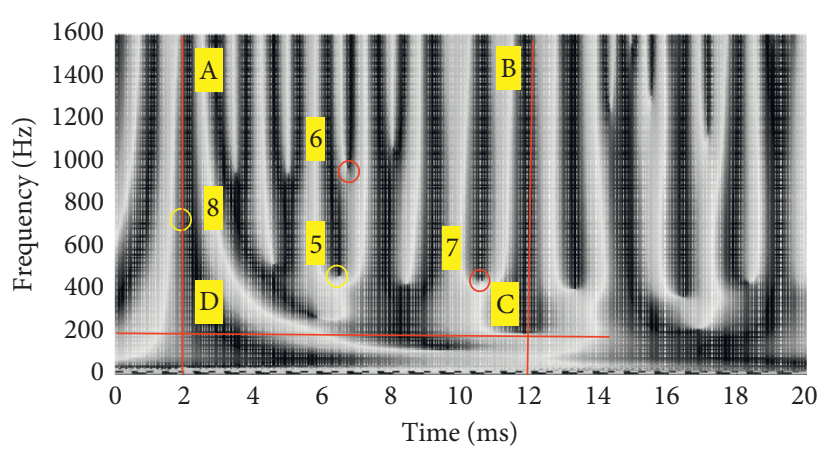

Figure 13: Grayscale images of phase angles.

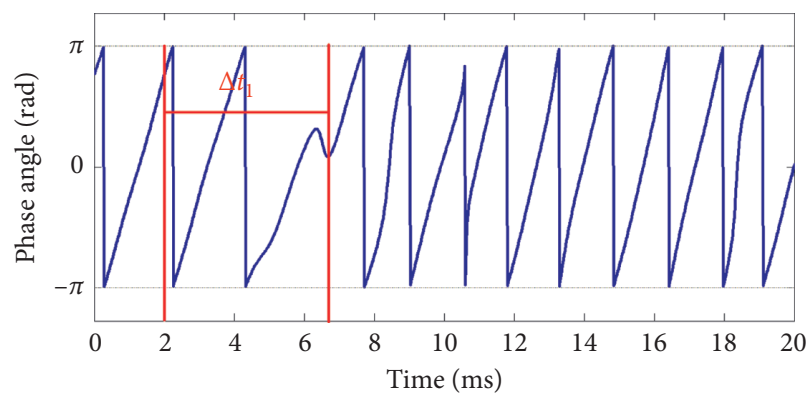

FIGURE 14: Time-phase angle curve with the frequency of $440 \mathrm{~Hz}$.

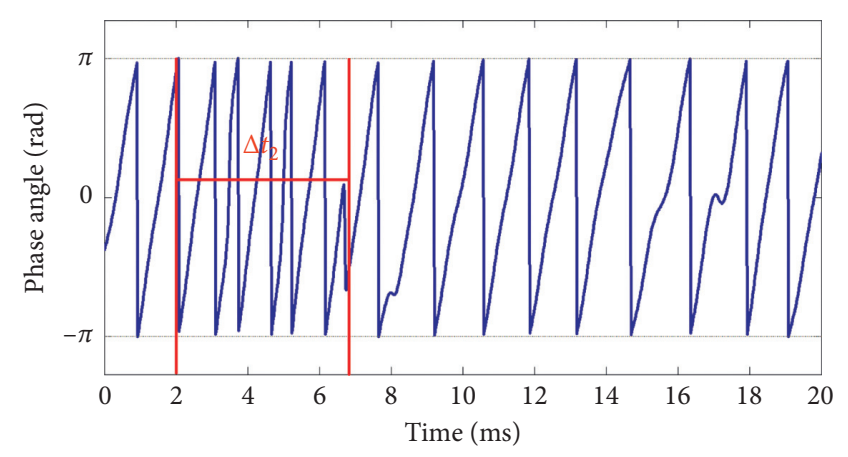

FIgURE 15: Time-phase angle curve with the frequency of $968 \mathrm{~Hz}$.

Point 8 and Points 6 and 7 are $4.8 \mathrm{~ms}$ and $8.8 \mathrm{~ms}$, respectively. Owing to the wave propagation velocity calculated as $c=3900 \mathrm{~m} / \mathrm{s}$ based on Young's modulus and the density of concrete, the corresponding distances from the damaged 


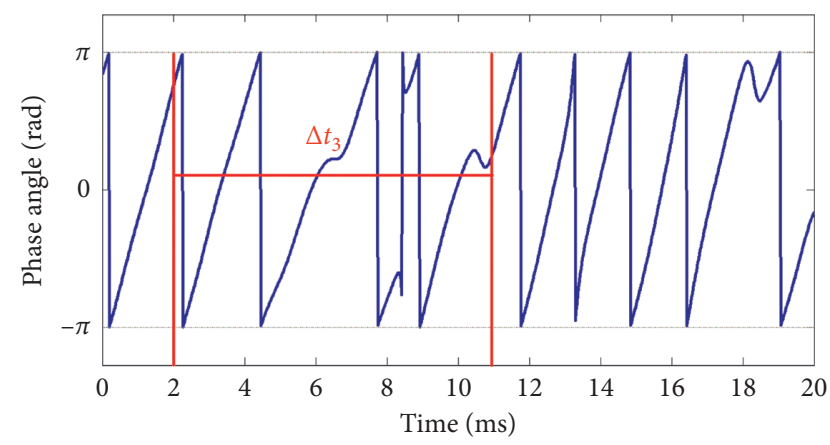

FIGURE 16: Time-phase angle curve with the frequency of $418 \mathrm{~Hz}$.

points to the top of the pile are computed to be $8.78 \mathrm{~m}$, $9.36 \mathrm{~m}$, and $17.16 \mathrm{~m}$, respectively. The previous damage localization results using the ultrasonic emission method indicate that the actual damage position is $8 \mathrm{~m}$ from the pile head, which confirms that Point 5 is the real phase angle turning point. The relative error between the damage localization results using the proposed method and the ultrasonic emission method is $9.75 \%$. By contrast, Points 6 and 7 can be judged as interference points and the reduction and even elimination of interference points need to be further investigated. A possible way is the mutual verification by comprehensive consideration of other pile damage detection methods and engineering experience.

\section{Conclusions}

CCWT is introduced in this paper to localize pile damage. Compared with the traditional damage detection method, the CCWT method highlights the phase information of response signals and has the potential to localize the positions of minor damage in the pile body. The two main contributions of this paper are as follows: (1) The application of the proposed damage localization method on an actual pile is verified. (2) A parameter analysis is performed to investigate the impact of the damage position on the accuracy of pile localization. To verify the accuracy and effectiveness of the CCWT-based pile damage localization method, a numerical example of the $3 \mathrm{D}$ finite element pile model and an experimental verification on an actual pile are investigated. The results demonstrate that the CCWT method is capable of localizing both simulated piles and actual piles; however, there are still some interference points in the grayscale images of phase angles. A possible way to address this issue is the mutual verification by comprehensive consideration of other pile damage detection methods and engineering experience. The results of parameter analysis show that the accuracy of damage localization increases when the damage approaches the middle of the pile body. In addition, the error is possible to increase tremendously when the distance between the damage position and the pile head is less than a quarter of the pile length.

\section{Data Availability}

The data used to support the findings of this study are available from the corresponding author upon request by email: liujingliang@fafu.edu.cn.

\section{Conflicts of Interest}

The authors declare that there are no conflicts of interest regarding the publication of this paper.

\section{Acknowledgments}

This work was sponsored by the National Natural Science Foundation of China (NSFC) under Grant no. 51608122, China Postdoctoral Science Foundation under Grant no. 2018M632561, Postdoctoral Science Foundation between Fujian and Taiwan under Grant no. 2018C002, the Outstanding Youth Fund of Fujian Agriculture and Forestry University under Grant no. XJQ201728, and the Open Project Fund of Sustainable and Innovative Bridge Engineering Research Center of Fujian Province University under Grant no. SIBERC 2018001.

\section{References}

[1] L. Q. Liang, S. Webster, and M. Bixier, "Recommendations on two acceleration measurements with low strain integrity test," in Proceedings of the IFCEE, Orlando, FL, USA, June 2018.

[2] A. G. Davis, "Nondestructive evaluation of existing deep foundations," Journal of Performance of Constructed Facilities, vol. 9, no. 1, pp. 57-74, 1995.

[3] D.-M. Cui, W. Yan, X.-Q. Wang, and L.-M. Lu, "Towards intelligent interpretation of low strain pile integrity testing results using machine learning techniques," Sensors, vol. 17, no. 11, pp. 24-43, 2017.

[4] K. Webster, F. Rausche, and S. Webster, "Pile and shaft integrity test results classification, mitigation, acceptance, and/ or rejection," in Proceedings of the Transportation Research Board Meeting, Washington, DC, USA, January 2011.

[5] G. Mullins, "Thermal integrity profiling of drilled shafts," DFI Journal-The Journal of the Deep Foundations Institute, vol. 4, no. 2, pp. 54-64, 2010.

[6] S.-H. Ni, Y.-Z. Yang, and C.-R. Lyu, "Application of wavelet transform for the impulse response of pile," Smart Structures and Systems, vol. 19, no. 5, pp. 513-521, 2017.

[7] X. Ding, H. Liu, J. Liu, and Y. Chen, "Wave propagation in a pipe pile for low-strain integrity testing," Journal of Engineering Mechanics, vol. 137, no. 9, pp. 598-609, 2011.

[8] N. Massoudi and W. Teferra, "Non-destructive testing of piles using the low strain integrity method," in Proceedings of the 5th International Conference on Case Histories in Geotechnical Engineering, pp. 13-17, Rolla, MO, USA, December 2014.

[9] C. Zheng, H. Liu, X. Ding, G. P. Kouretzis, S. W. Sloan, and H. G. Poulos, "Non-axisymmetric response of piles in lowstrain integrity testing," Géotechnique, vol. 67, no. 2, pp. 181-186, 2016.

[10] S. W. Hou, S. J. Hu, S. P. Guo et al., "The research of multidefective piles for low strain testing and numerical simulation," in Proceedings of the 2016 Structures Congress, Seogwipo-si, Korea, February 2016.

[11] C. Zheng, H. Liu, G. P. Kouretzis, S. W. Sloan, and X. Ding, "Vertical response of a thin-walled pipe pile embedded in viscoelastic soil to a transient point load with application to low-strain integrity testing," Computers and Geotechnics, vol. 70, pp. 50-59, 2015.

[12] S.-H. Ni, Y.-Z. Yang, P.-H. Tsai, and W.-H. Chou, "Evaluation of pile defects using complex continuous wavelet transform analysis," NDT \& E International, vol. 87, pp. 50-59, 2017. 
[13] L. D. Olson and C. C. Wright, "Nondestructive testing of deep foundations with sonic methods," in Proceedings of the Foundation Engineering Congress: Current Principles and Practice, Evanston, IL, USA, June 1989.

[14] J. Xu, Q. Ren, Z. Shen et al., "Low strain pile testing based on synchrosqueezing wavelet transformation analysis," Journal of Vibroengineering, vol. 18, no. 2, pp. 813-825, 2016.

[15] S.-H. Ni, K.-F. Lo, L. Lehmann, and Y.-H. Huang, "Timefrequency analyses of pile-integrity testing using wavelet transform," Computers and Geotechnics, vol. 35, no. 4, pp. 600-607, 2008.

[16] S. H. Ni, W. M. Isenhower, and Y. H. Huang, "Continuous wavelet transform technique for low strain integrity testing of deep drilled shafts," Journal of Geoengineering, vol. 7, no. 3, pp. 97-105, 2012.

[17] H. L. Qu, Y. Liu, H. Luo, H. Hu, and Q. Hu, "Seismic response characteristics of stabilizing pile based on elastic-plastic analysis," Shock and Vibration, vol. 2018, Article ID 7672587 , 15 pages, 2018.

[18] B. Chen, Y. P. Kang, P. Y. Li, and W. P. Xie, "Detection on structural sudden damage using continuous wavelet transform and Lipschitz exponent," Shock and Vibration, vol. 2015, Article ID 832738, 17 pages, 2015.

[19] D. Boulahbal, M. F. Golnaraghi, and F. Ismail, "Amplitude and phase wavelet maps for the detection of cracks in geared systems," Mechanical Systems and Signal Processing, vol. 13, no. 3, pp. 423-436, 1999.

[20] H. Hibbitt, B. Karlsson, and P. Sorensen, "ABAQUS theory manual: Version 6.12," 2012.

[21] J. Liu, Z. Guo, N. Zhu et al., "Dynamic response of offshore open-ended pile under lateral cyclic loadings," Journal of Marine Science and Engineering, vol. 7, no. 5, pp. 128-146, 2019.

[22] E. Cabella and R. Passalacqua, "Axially loaded pile numerical models vs. experimental data," Application of Numerical Methods to Geotechnical Problems, Polytechnic University of Milano, Milano, Italy, pp. 97-106, 1998.

[23] M. T. A. Chaudhary and Y. Fujino, "System identification of bridges using recorded seismic data and its application in structural health monitoring," Structural Control and Health Monitoring, vol. 15, no. 7, pp. 1021-1035, 2010. 